\title{
A MASTECTOMIA E A RESSIGNIFICAÇÃO DO CORPO NO FEMININO
}

\author{
Dayane Pereira*, Ana Aparecida Martinelli Braga** \\ Autor correspondente: Dayane Pereira - dayane.psic@gmail.com \\ * Escola Bahiana de Medicina e Saúde Pública \\ ** Professora da Escola Bahiana de Medicina e Saúde Pública
}

\begin{abstract}
Resumo
O câncer de mama é o segundo tipo de câncer mais frequente no mundo e o mais comum entre as mulheres. A cirurgia de mastectomia é o mais invasivo dos tratamentos cirúrgicos para esta patologia, e traz sérias implicações para a paciente. Este trabalho visa abordar questões referentes às estratégias de enfrentamento utilizadas no processo de adoecimento, bem como a percepção das pacientes sobre sua autoimagem pré e pós cirúrgica; identificar impactos psicológicos, físicos e sociais causados pela cirurgia e pelo tratamento quimioterápico; avaliar as percepções referentes à temática da morte e às dimensões do medo que este tema desperta. O estudo contou com levantamento bibliográfico e pesquisa de campo, na qual a coleta de dados foi feita através de entrevista semiestruturada, aplicada em dois momentos - antes e depois da cirurgia - em quatro participantes que estavam em tratamento oncológico em clínica particular de Salvador - BA. Com os dados obtidos, foram selecionadas quatro categorias de análise. Como resultado, concluiu-se que o recebimento do diagnóstico de câncer fez com que a paciente refletisse sobre questões como o sentido da sua vida e o medo da morte; para elas a estética não diz respeito apenas ao que é belo, mas se refere à identificação com o feminino; observou-se também que a crença em Deus é algo que possibilita e potencializa o estabelecimento da confiança no tratamento e na possibilidade de cura; e que a atuação da equipe multidisciplinar de assistência pode otimizar o tratamento quando esta trabalha de forma humanizada.

Palavras-chave: Mastectomia; Corpo; Ressignificação corporal; Câncer de mama.
\end{abstract}




\title{
THE MASTECTOMY AND THE CORPORAL REFRAIMING IN A FEMININE BODY
}

\begin{abstract}
The Breast Cancer is the second most frequent type of cancer around the world and the most common amongst women. The mastectomy surgery is the most invasive from all surgical treatments for this kind of pathology, and it brings serious implications to the patient. This article aims to comprehend the corporal reframing in women that undergone this procedure, as well look the patient perception about her self-image and their self-awareness on the prior and post stages of the surgery; identify the psychological impacts caused by the surgery; evaluate the impacts of the surgery and the breast cancer itself in the social life of the patient. The study counted in literature researches and field researches, in which a database was structured through a semi-structured interview, applied at two distinct moments - before and after the surgery - with four participants that were under oncologic treatment in Salvador- BA. With the obtained data, it was chosen four categories for analysis. As a result, it was concluded that receiving the diagnostic for cancer made the patients reflect about question like the meaning of life and the fear of death; To the patients, aesthetics doesn't concern only what is beautiful, but reflects the identification with the feminine; it was also observed that the belief in God is something that manages and improves the establishment of trust in the treatment and in the possibility of a cure; and the actions of a multidisciplinary care team may optimize the treatment when they work in a human way.
\end{abstract}

Keywords: Mastectomy; Body; Corporal reframing; Breast cancer.

\section{INTRODUÇÃO}

O Câncer de Mama é o segundo tipo de câncer mais frequente no mundo e o mais comum entre as mulheres, ele é responsável por $22 \%$ dos novos casos da doença a cada ano. No Brasil, as taxas de mortalidade relacionadas a esta patologia ainda são elevadas, em 2008 foram 11.860 mortes, sendo 11.735 mulheres e 125 homens. Para 2010, estima-se o aparecimento de 49.240 novos casos no Brasil. Este é um câncer relativamente raro antes dos 35 anos de idade, no entanto acima desta faixa a incidência cresce rápida e progressivamente. ${ }^{(1)}$

Indica-se que o câncer de mama seja abordado por uma equipe multidisciplinar, a fim de promover ao paciente o tratamento mais integral possível. Os tratamentos médicos disponíveis atualmente são cirurgia e radioterapia para o tratamento loco-regional, e hormonioterapia e quimioterapia para o tratamento sistêmico. A indicação cirúrgica como tratamento para o câncer de mama envolve diferentes tipos de cirurgia, que vai depender do estágio clínico e do tipo histológico (local onde está situado) da doença. ${ }^{(2)}$

As possibilidades de cirurgia neste caso se dividem em dois tipos: Conservadoras ou Não-conservadoras. O primeiro tipo engloba a tumorectomia (retirada apenas do tumor sem margens de segurança) e a ressecção segmentar ou setorectomia (retirada do tumor e de margens de segurança). Já o segundo inclui a adenomastectomia subcutânea ou mastectomia subcutânea (retirada de glândula 
mamária com preservação da pele e da aréola), a mastectomia simples ou total (retirada da mama juntamente com pele e aréola), a mastectomia radical modificada (retirada da mama com preservação de um ou dois músculos peitorais e esvaziamento dos gânglios axilares) e a mastectomia radical (retirada da mama e dos músculos peitorais com esvaziamento dos gânglios axilares). ${ }^{(3)}$

A cirurgia de mastectomia, o mais invasivo dos tratamentos cirúrgicos para o câncer de mama, traz sérias implicações para a vida da paciente. Embora este não seja um recurso utilizado em todos os casos, ele é bastante freqüente. A mastectomia gera repercussões emocionais importantes, alterando não somente a imagem física, como também a imagem psíquica que a paciente tem de si mesma. ${ }^{(4)}$

O corpo humano sente, fala, percebe, vive e pode ser compreendido de diversas formas. ${ }^{5)} \mathrm{A}$ imagem que cada um faz do seu corpo é um complexo fenômeno que envolve diversos aspectos: cognitivos, afetivos, sociais, culturais e motores. Este fenômeno está intimamente ligado ao conceito que se tem de si próprio e é influenciado pelas dinâmicas interações do indivíduo com o meio no qual está inserido. O processo de desenvolvimento da auto-imagem está relacionado, nas diferentes fases da existência humana, sobretudo aos conceitos determinados pela cultura e pela sociedade vigente. $^{(6)}$

O presente artigo ancora sua relevância no fato de que a(o) profissional de Psicologia pode se deparar com uma variedade muito grande de patologias, diagnósticos e prognósticos médicos dos pacientes oncológicos, e eventualmente uma mutilação física pode ser consequência de algum desses processos. É necessário que ela(ele) possa compreender melhor os sentimentos marcantes e significativos desta fase, bem como as diferentes reações psicológicas que podem acompanhar esta alteração física. ${ }^{(7)}$

Considerando-se o corpo como representante da subjetividade do indivíduo, esta pesquisa visa abordar questões referentes às estratégias de en- frentamento utilizadas pelas pacientes no processo de adoecimento da mama, bem como a percepção da sua autoimagem antes e depois da cirurgia de mastectomia; identificar impactos psicológicos, físicos e sociais causados pelo tratamento cirúrgico e quimioterápico; avaliar as percepções referentes à temática da morte e às dimensões do medo que este tema desperta. Deste modo, para o referido tema, coube como ponto de partida o questionamento sobre o desenvolvimento da ressignificação do corpo em mulheres que passaram pelo procedimento de mastectomia em decorrência do diagnóstico de câncer de mama.

A mastectomia, bem como qualquer tipo de amputação, é um procedimento invasivo e doloroso física e psicologicamente, pois retira da pessoa parte do seu corpo. Devido a isso, é preciso elaborar o luto daquela perda e ressignificar o sentido daquele órgão e, muitas vezes, da própria vida, a fim de ter perspectiva e condições para se reabilitar.

Este trabalho pode também ampliar os conhecimentos acerca dos aspectos psíquicos implicados nesta mutilação física, tanto dos próprios psicólogos e da equipe de saúde que trabalham com pacientes mastectomizadas, quanto dos pacientes $\mathrm{e}$ de seus familiares sobre esta temática.

\section{METODOLOGIA}

\subsection{CARACTERIZAÇÃO DOS SUJEITOS E DA INSTITUIÇÃOO}

Este estudo foi realizado com o4 (quatro) pacientes diagnosticadas com câncer de mama que tiveram indicação de cirurgia de mastectomia e já realizavam tratamento oncológico em clínica particular de assistência especializada. Para isto, foram delimitados os seguintes critérios de inclusão: os pacientes deveriam ser do sexo feminino; ter idade entre 18 e 70 anos, mas diante do contexto da clínica, as participantes tiveram em média 50 anos; terem sido diagnosticadas com câncer de mama e 
terem indicação de mastectomia (uni ou bilateral) confirmada pelo médico assistente.

Foram também delimitados alguns critérios de exclusão para a participação neste estudo, quais sejam: as pacientes que iriam realizar mastectomia profilática, também chamada de mastectomia preventiva; e pacientes com histórico prévio de qualquer transtorno psicológico.

Com os dados demográficos das pacientes participantes foi possível construir o Quadro 1:

Quadro 1 - Dados demográficos das pacientes participantes

\begin{tabular}{|c|c|c|c|c|c|c|c|}
\hline NOME & $\begin{array}{c}\text { DATA DE } \\
\text { NASCIMENTO }\end{array}$ & IDADE & $\begin{array}{c}\text { LOCAL DE } \\
\text { NASCIMENTO }\end{array}$ & $\begin{array}{c}\text { ESTADO } \\
\text { CIVIL }\end{array}$ & $\begin{array}{c}\text { N.o DE } \\
\text { FILHOS }\end{array}$ & ESCOLARIDADE & PROFISSÃO \\
\hline Paciente O1 & O4.04.1956 & 55 anos & Juazeiro - Ba & Casada & O2 & $\begin{array}{c}3^{\circ} \text { Grau } \\
\text { Completo }\end{array}$ & $\begin{array}{c}\text { Pedagoga } \\
\text { aposentada }\end{array}$ \\
\hline Paciente O2 & 24.06 .1961 & 50 anos & Chorrochó - Ba & Divorciada & O2 & $\begin{array}{c}3^{\circ} \text { Grau } \\
\text { Completo }\end{array}$ & Pedagoga \\
\hline Paciente O3 & 29.09 .1961 & 50 anos & Salvador - Ba & Viúva & O3 & $\begin{array}{c}3^{\circ} \text { Grau } \\
\text { Completo }\end{array}$ & Pedagoga \\
\hline Paciente O4 & O7.11.1955 & 56 anos & Salvador - Ba & Divorciada & O2 & $\begin{array}{c}3^{\circ} \text { Grau } \\
\text { Completo }\end{array}$ & $\begin{array}{c}\text { Pedagoga e } \\
\text { Secretária } \\
\text { Executiva }\end{array}$ \\
\hline
\end{tabular}

\subsection{ESTRATÉGIA DE COLETA DE DADOS E ANÁLISE DOS DADOS COLETADOS}

A coleta de dados da pesquisa foi feita através da realização de entrevistas semi-estruturadas, divididas em duas etapas. A primeira etapa foi realizada em média uma semana antes de a paciente se submeter ao procedimento cirúrgico e a segunda cerca de 02 (dois) meses após a realização da cirurgia. Na primeira e na segunda entrevistas foram priorizadas as mesmas temáticas, a fim de haver a comparação desse material.

A escolha da entrevista como técnica de coleta de dados se deve por tratar-se de um método que valoriza e privilegia a fala do sujeito da pesquisa e a escuta do entrevistador, sendo este o momento para entendimento e construção de sentidos das vivências reais e pessoais deste sujeito. A opção de criar perguntas semi-estruturadas ocorre para que haja um nível de direcionamento das temáticas abordadas no decorrer da entrevista, pois se trata de uma pesquisa científica que deve considerar seus objetivos propostos. No entanto, vale res- saltar que o propósito deste direcionamento não é determinar a fala do indivíduo, mas fazer com que seu discurso não fuja dos objetivos do estudo. ${ }^{\left({ }^{(8)}\right.}$

As entrevistas foram aplicadas pela pesquisadora responsável individualmente, em ambiente reservado. Os discursos tiveram registro em áudio, e posteriormente foram transcritos, categorizados e interpretados através da análise de discurso proposta por Minayo. ${ }^{(9)}$ A gravação em áudio justificou-se pela transcrição literal da fala da paciente, o que possibilitou uma melhor análise do conteúdo narrado, ainda que os discursos não serão utilizados para nenhum outro fim que não este.

\subsection{CONSIDERAÇÕES ÉTICAS}

Por se tratar de pesquisa envolvendo seres humanos, o projeto foi encaminhado para o Comitê de Ética em Pesquisa do Hospital Espanhol, para que fosse avaliado. Foi necessário que cada sujeito, ao aceitar participar da pesquisa, assinasse o Termo de Consentimento Livre e Esclarecido (TCLE), comprovando o seu conhecimento acerca dos pa- 
râmetros do estudo e atestando a concordância da sua participação. Priorizou-se a realização das entrevistas em uma sala reservada.

\subsection{DO ARQUIVAMENTO DE DADOS}

Os relatos escritos, bem como os registros em áudio, obtidos através das entrevistas, serão armazenados em local adequado.

\section{QUANDO O CÂNCER SE INSCREVE NO CORPO}

\subsection{O CÂNCER DE MAMA}

A palavra câncer, do grego Karkinos (caranguejo), é o nome genérico para designar neoplasias (tumores) malignas. $O$ crescimento da célula cancerígena é desordenado e descontrolado, compromete todo organismo, desequilibrando-o funcionalmente, fazendo surgir sintomas, morbidade e, por vezes, mortalidade. ${ }^{(10)}$

O câncer de mama é a malignidade não-cutânea mais freqüente no mundo e o mais comum entre as mulheres, ele é responsável por $22 \%$ dos novos casos da doença a cada ano. Em 2001, ele atingiu cerca de 240.000 mulheres e mais de 40.000 morreram em decorrência da doença. Estima-se que uma mulher que vive 90 anos de idade tem uma chance em oito de desenvolver esta patologia. ${ }^{(11)}$ No Brasil, as taxas de mortalidade relacionadas a esta patologia ainda são elevadas, em 2008 foram 11.860 mortes, sendo 11.735 mulheres e 125 homens. Para 2010, estima-se o aparecimento de 49.240 novos casos no Brasil. Este é um câncer relativamente raro antes dos 35 anos de idade, no entanto acima desta faixa a incidência cresce rápida e progressivamente. No entanto, se diagnosticado e tratado oportunamente, o prognóstico é relativamente bom. ${ }^{(1)}$

Os sintomas do câncer de mama vão desde a percepção de tumoração ou nódulo no seio ou axi- la, acompanhado ou não de dor, até a presença de abaulamentos e retração mamária com aspecto de casca de laranja. ${ }^{(10)} \mathrm{O}$ câncer de mama tem como tratamento principal a cirurgia (mastectomia ou retirada de algum segmento da mama com ou sem retirada de linfonodos axilares) que geralmente é seguida de tratamento complementar ou adjuvante, com quimioterapia e/ou radioterapia ou hormonioterapia, a depender do grau histológico e da disseminação da doença (estadiamento), da dosagem de receptores hormonais, da idade, status menstrual e do estado geral. ${ }^{(12)}$

\subsection{ALÉM DO FÍSICO, O CORPO PSICOLÓGICO}

Ao longo da História da Humanidade, a espécie humana passou por diversas modificações estruturais, chegando à aparência física que temos hoje. O esquema corporal é a imagem tridimensional do corpo de um indivíduo, sem considerar-se a sensação ou a imaginação. Esse esquema é apreendido através dos sentidos, mas não se trata de uma simples percepção, é ele que especifica o indivíduo como pertencente à espécie humana, em qualquer lugar, época ou contexto em que ele esteja inserido. Este esquema está relacionado à estrutura neurológica do indivíduo e é responsável pelas informações proprioceptivas que permitem o reconhecimento do corpo anatômico. O mesmo é constituído paulatinamente, começa a se desenvolver antes mesmo do nascimento e vai se desenvolvendo e evoluindo adaptativamente por toda a existência do sujeito. (7) No entanto, o ser humano não é constituído apenas por uma estrutura corporal física e concreta, o homem é um ser complexo, que, para existir, passa por muitas dimensões.

O corpo humano, com o qual se ocupa a Ciência, é dotado de diversos sistemas articulados entre si que tem a função de manter a vida, afastando a possibilidade de morte. Um corpo que não aponta para o sujeito do inconsciente, ou seja, o corpo da ciência, não demanda um deciframento simbólico. ${ }^{(13)}$ Em contrapartida, Freud em 1895, em seus Estudos 
sobre a Histeria, compreende o corpo não somente em sua dimensão física, mas, sobretudo, em sua dimensão subjetiva advinda do imaginário social. O corpo é tomado como evidenciador de questões íntimas e inconscientes, portanto, o que o corpo mostra vai além daquilo que é visível. Deste modo, Freud abre as portas para uma nova compreensão do conceito de corpo e de suas possibilidades, rompendo com a Medicina clássica. "O corpo fala" ${ }^{(13)} \mathrm{e}$ por dizer de si, ele se torna simbólico e passível de compreensão, sobretudo através da linguagem.

Segundo Reich, ${ }^{(14)}$ "O corpo é o inconsciente visível". Nesse sentido, o corpo pode ser elevado a sua condição mais subjetiva. O corpo evidencia inúmeras questões com relação ao indivíduo, tais como suas crenças, valores, fantasias, ideais, enfim, tudo permeia, em algum nível, a estrutura corpórea. Não há nada relacionado ao ser humano que não passe pela dimensão corporal.

Leloup, ${ }^{(5)}$ em seu livro O Corpo e Seus Símbolos, traz uma visão abrangente da noção de corpo. Ele o compara com uma escada, na qual as partes mais altas se apoiam nas mais baixas, por isso, o corpo precisa estar totalmente saudável para se manter vivo. Leloup ${ }^{(5)}$ propõe um paralelo entre a escada evolutiva da consciência e a escada do nosso corpo, e com isso ele demonstra e comprova que as etapas pelas quais passamos desde a vida intra-uterina reverberam no nosso desenvolvimento por toda a vida. Cada parte do nosso corpo traduz memórias e traz significados que talvez fujam à nossa compreensão.

A imagem corporal, diferentemente do esquema corporal, está ligada ao sujeito e à sua história e, portanto, é única para cada um. Esta imagem tem a ver com a relação afetiva que cada indivíduo tem com seu corpo, ela é fruto das vivências e das relações interpessoais. A imagem que se faz do corpo é o ponto inicial para a construção da identidade e para a elaboração de um autoconceito. Esta é formada através da relação entre a imagem que se deseja ter, a imagem representada pelos outros e a imagem que se reconhece ao se olhar o próprio corpo. Deste modo, a imagem corporal se forma no imaginário do sujeito, no contato dele com o mundo e consigo mesmo, mas não é somente imaginação, é a figuração do corpo na sua mente e, para isso, são necessárias contribuições fisiológicas, anatômicas, neurológicas, sociológicas, entre outras. ${ }^{(7)}$

"A coisa mais importante para nós é o nosso corpo", assim afirma J.-D. Nasio. (15) Para esse autor, o corpo que temos é fruto da nossa fantasia e quando o vemos ou o sentimos estamos traçando uma imagem deformada dele, e essa deformação se deve aos sentimentos que estão envolvidos na percepção desse corpo. Um objeto que é construído como identidade.

O corpo com o qual se nasce é um esboço da imagem elaborada pelos pais e familiares, sob forte influência da cultura. No entanto, essa imagem elaborada não corresponde ao corpo concreto, a identidade corporal se desenvolve através das vivências e das sensações, e o corpo se desenvolve a partir de suas potencialidades e das limitações impostas pelo meio externo. ${ }^{(16)}$ Neste sentido, ele se põe em constante mudança, estando sempre exposto a transformações.

\subsection{AS TRANSFORMAÇÕES IRREVERSÍVEIS DO CORPO}

O termo "Transformação" - do latim transformatione = trans ("movimento para além de", "através de", "posição para além de") + formatione ("ato, efeito ou modo de formar") - é definido pelo Novo Dicionário da Língua Portuguesa ${ }^{(17)}$ como:

\footnotetext{
1. Ato ou efeito de transformar(-se); metamorfose;

2. [Física] Modificação do estado de um sistema;

3. [Genética] Transferência de material genético de uma bactéria para outra através de ácido desoxirribonucléico extracelular; 4. [Linguística] Regra linguística que muda uma estrutura em outra; 5. [Matemática] Qualquer operação em que se modifica um ente matemático, ou em que se mapeia uma configuração em outra. ${ }^{(16)}$
} 
Muitos podem ser os procedimentos aos quais o indivíduo pode ser submetido para que haja alguma transformação definitiva do seu corpo. $O$ paciente que passa por algum processo cirúrgico de retirada de parte do seu corpo sofre alteração, tanto no seu esquema corporal, quanto na sua imagem corporal e, com isso, após a cirurgia, ele necessita reconstruir sua imagem corporal e a concepção que tem de si mesmo. ${ }^{(7)}$

A falta de uma parte faz com que as pessoas tragam em seus corpos sinais que as identificam como diferentes, imperfeitas e incapazes. ${ }^{(16)} \mathrm{Se}-$ gundo Chini e Boemer, ${ }^{(18)}$ a perda de parte do corpo é um processo doloroso que convoca o indivíduo à reorganização do modo de viver e de se relacionar. A amputação - ou a retirada de alguma parte externa do corpo - altera toda a existência do sujeito e impõe uma constante readaptação ao mundo, ela faz com que o indivíduo amputado assuma uma nova perspectiva do mundo para si, para os demais e para os objetos.

Chini e Boemer ${ }^{(18)}$ definem a amputação como sendo um procedimento que traz ao paciente sentimentos bons e ruins, pois, embora exista a perda de uma parte do corpo, existe a recuperação da dinâmica da vida e a possibilidade de manutenção da mesma. A amputação gera uma mudança permanente na aparência do sujeito, em sua autoimagem. É necessário que ele aprenda a conviver com as situações do cotidiano, reconstruindo suas possibilidades motoras para cada situação, numa constante adaptação dessa nova condição corporal. ${ }^{(16)}$

Segundo González Rey, ${ }^{(20)}$ o ser humano é compreendido como um indivíduo sociocultural, deste modo, ele é colocado como elemento integrante e fundamental da sua sociedade. A subjetividade e o estudo da relevância da sua construção no processo de identidade do sujeito estiveram um pouco adormecidos na Psicologia durante algumas décadas, abrindo espaço para uma Psicologia de base empírica e experimental. No entanto, foi desde a Psicologia Soviética, aproveitando-se das condições geradas pela Revolução Russa, que este tema vem sendo colocado como pauta de discussão e de elaborações teóricas.

A subjetividade, como sistema complexo e multideterminado, é afetada pela sociedade e pelos indivíduos que a constituem dentro da dinâmica rede de relações que fundamentam o desenvolvimento social. Ela é, então, compreendida como uma dimensão sistêmica, dialética, dialógica e complexa que deve ser exaustivamente estudada e valorizada pela Psicologia. ${ }^{(20)}$

Desta maneira, percebemos que a subjetividade é construída considerando-se diversos conceitos e valores que vão sendo estabelecidos desde a primeira infância. As transformações físicas pelas quais se passa ao longo da vida, sejam elas por livre escolha ou por necessidade, interferem nessa construção e na identidade do sujeito, o que pode causar alterações na sua auto-percepção e na sua percepção do mundo.

\section{ANÁLISE E DISCUSSÃO}

A integração do psicólogo à equipe de assistência a pacientes oncológicos é de grande valia. O trabaIho deste profissional vem no sentido de acolher o sofrimento gerado por este processo e potencializar a reflexão daquele momento da história de vida do paciente, resgatando o seu lugar no mundo enquanto sujeito, para que ele possa continuar identificando a si mesmo para além do câncer.

Diante do estudo feito durante a trajetória de realização desta pesquisa, e analisando as falas trazidas pelas pacientes nas entrevistas, foi possível avaliar os conteúdos mais recorrentes nos discursos delas. Através desta análise, se chegou a quatro categorias temáticas, que serão apresentadas a seguir:

\subsection{A FÉ COMO ESTRATÉGIA DE ENFRENTAMENTO}

Um processo de adoecimento, qualquer que ele seja, é, sem dúvida, um evento estressor na vida 
de quem o vivencia. Ele pode trazer implicações físicas, psicológicas, sociais, entre outras. Deste modo, o que pode fazer a diferença na relação do sujeito com a sua enfermidade é o enfrentamento que ele desenvolve diante da mesma. As estratégias de enfrentamento passam a ser observadas quando o indivíduo está tentando superar o que está lhe causando estresse. ${ }^{(21,22)}$

Segundo Costa e Leite, ${ }^{(21)}$ enfrentamento é um processo pelo qual o paciente pode administrar as demandas estressoras da sua relação com o ambiente, bem como as emoções que elas geram. Folkman, Lazarus, Gruen e De Longis ${ }^{(23)}$ trazem que o enfrentamento é uma série de esforços cognitivos e comportamentais direcionados ao manejo de exigências internas e/ou externas consideradas como sobrecarga aos recursos pessoais do sujeito. As estratégias de enfrentamento podem ser classificadas em duas categorias principais que são: o enfrentamento centrado no problema, através do qual o indivíduo procura meios para modificar ou manejar a situação causadora de estresse; e o enfrentamento centrado na emoção, que tem como função principal regular a resposta emocional gerada pelo evento estressor, a fim de reduzir a sensação física desagradável causada pelo estresse. ${ }^{(21,22)}$

A utilização de técnicas cirúrgicas, quimioterápicas, radioterápicas e biológicas para o tratamento dos pacientes diagnosticados com câncer resulta na cura de mais de $50 \%$ dos casos. No entanto, se a força poderosa da mente for invocada e esta for aliada à fé religiosa, visando a recuperação da enfermidade, o paciente tenderá a se sentir mais feliz e com outra disposição para enfrentar a doença, podendo, dessa forma, provocar alteração em seu quadro clínico. ${ }^{(21)}$

Pargament et al (24) afirmam que a utilização da religião como enfrentamento pode assumir funções diversas nos diferentes estilos de solução de problemas desenvolvidos por cada sujeito. Estas funções vão variar de acordo com o nível de responsabilização e participação da pessoa na resolução do seu problema. Estas autoras descrevem três principais estilos de enfrentamento: o Autodirigido (no qual a responsabilidade de resolver o problema é do sujeito e compreende-se que Deus concede liberdade para se conduzir a própria vida); o Delegante (no qual o indivíduo transfere a responsabilidade da resolução do seu problema para Deus); e o Colaborativo (no qual a responsabilidade é atribuída tanto à Deus quanto ao paciente, sendo ambos ativos na resolução do problema).

Em linhas gerais, a religião ocupa um espaço importante na vida das pessoas, e a religiosidade pode ajudá-las a encontrar seu significado e sua coerência no mundo. $O$ suporte religioso, utilizado como estratégia de enfrentamento, pode promover o fortalecimento da fé e consequentemente desencadear pensamentos mais otimistas, o que poderá diminuir a tensão interna gerada pelo processo de adoecimento. Pesquisas sistemáticas têm confirmado quantitativamente que a religião é um fator de proteção. ${ }^{(21)}$

Por se tratar de algo construído a partir da personalidade de cada ser humano, a espiritualidade expressa a identidade em função da história pessoal, experiências e aspirações. Deste modo, a religião tende a diminuir o sofrimento, ao passo que permite mudar a perspectiva subjetiva, na qual o paciente vivencia a doença. A fé em Deus constitui um modo de pensar construtivo que desencadeia uma sensação de confiança de que acontecerá o que se deseja, este é um sentimento muito presente em nossa cultura e é tão necessária quanto outros modos de enfrentamento. ${ }^{(21)}$

A partir do conteúdo trazido pelas entrevistadas, nota-se que o suporte religioso ocupa um lugar de destaque na vida delas, o que indica que é imprescindível reconhecer o papel da espiritualidade quando se pensa sobre a assistência em saúde. A Paciente 01, por exemplo, nos dois momentos em que foi entrevistada, traz fortemente em seu discurso o lugar que a fé e a religião ocupam em sua vida, ela coloca a fé e a crença em Deus como alicerces para sua recuperação:

E eu, graças a Deus, eu não tive essas reações, não tive essa coisa assim, de me sentir impossibilitada, de ter que parar em hospital. Graças a Deus não. 
De vomitar, né? Essa coisa assim, de jeito nenhum, eu ficava assim, é, me sentia indisposta, né? Mas não ao ponto de ter que parar em emergência e graças a Deus, normal, pra mim foi normal. Eu fiz quimioterapia, eu fiz radioterapia. É tanto que também fui muito agraciada porque eu fiz 26 sessões de radioterapia e não fiquei com nenhuma lesão, nem ferir, eu não feri. Então, eu tenho mais é que agradecer, né? A Deus. E tô aqui, né?

E ainda, durante as entrevistas, foi percebida a vivência da espiritualidade como aspecto facilitador de uma reflexão sobre o adoecimento/ tratamento, tal como diz a Paciente 04 :

[...] eu reflito muito sobre isso, tem a minha, eu não digo religião, mas o que eu creio, que é em Deus, eu creio, eu sou evangélica e isso que tem me dado um suporte maior, mas ao mesmo tempo que eu sei, que eu tenho a fé e que sei que Deus me deu mais uma oportunidade de vida, né?

Ao analisar as entrevistas e tomando como base a literatura sobre o tema, confirma-se que a fé tem papel fundamental na organização psíquica do indivíduo que vivencia um adoecimento, em todas as fases: do diagnóstico à alta médica. Também se pode perceber que a fé em Deus é um forte ponto de apoio no que concerne à ressignificação do adoecimento, fase que virá posteriormente às etapas de tratamento, na qual o indivíduo poderá reavaliar a experiência da doença no sentido de tomá-la como uma possibilidade de crescimento pessoal e/ou espiritual.

A preocupação com a espiritualidade do paciente deve ser algo atualizado nas equipes médicas de assistência, sobretudo na área oncológica. Pensar o paciente de maneira holística é também compreender aspectos ligados a sua religião/espiritualidade, pois, uma vez que nos damos conta disto podemos entender determinados comportamentos deste e de seus familiares, bem como estar mais próximos da sua realidade psíquica e de suas crenças, o que poderá facilitar a comunicação com a equipe.

\subsection{O FEMININO E SUA ESTÉTICA}

O câncer, em suas diversas formas de apresentação e localização no corpo, constitui-se, ainda hoje, como um desafio para a Medicina no que se refere à prevenção e à terapêutica. $\mathrm{O}$ câncer de mama particularmente, além de ter a representação social de uma potencial ameaça de morte, comum a todos os cânceres, compromete um dos órgãos mais sensíveis do corpo da mulher: o seio. Ele representa um elemento importante para a diferenciação entre os sexos e, portanto, é considerado como um dos símbolos da identidade feminina. Além disso, sua função no aleitamento lhe confere um sentido de veículo de vida e de amor. Sendo assim, a ameaça de perdê-lo, ou a experiência efetiva de sua perda aumenta consideravelmente o impacto da doença no psiquismo da mulher. ${ }^{(25)}$

Segundo Capisano, ${ }^{(26)}$ a imagem corporal que cada sujeito faz de si passa pela imagem corporal de outros corpos. Adami(6) traz que a imagem que cada um faz do seu corpo é um complexo fenômeno que envolve diversos aspectos: cognitivos, afetivos, sociais, culturais e motores. Este fenômeno está intimamente ligado ao conceito que se tem de si próprio e é influenciado pelas dinâmicas interações do indivíduo com o meio no qual está inserido. Este autor traz, ainda, que o processo de desenvolvimento da autoimagem está relacionado, nas diferentes fases da existência humana, sobretudo aos conceitos determinados pela cultura e pela sociedade vigente.

Sontag ${ }^{(27)}$ ressalta que o câncer é uma doença que, comumente, se refere mais ao espaço que ocupa do que ao tempo que permanece, o que faz com que seja referenciada através de metáforas alusivas à topografia do corpo, tais como uma doença que se espalha, se prolifera, na qual os tumores são extirpados, etc. Esta patologia geralmente é associada à morte e à presença inexorável de dor, bem como pode ser ligado à necessidade de cirurgia de amputação ou algum tipo de mutilação.

A retirada da mama, órgão símbolo da identidade feminina, faz com que a imagem corporal da paciente se afaste do padrão de normalidade para 
um corpo feminino e dos ideais de feminilidade que tendem a priorizar sempre a beleza e a sedução como a essência da mulher. ${ }^{(27)}$

Em muitos casos o tratamento do câncer pode gerar alguma mutilação física, o que implica seqüelas, muitas vezes, irreversíveis. A maneira como cada um lida com situações difíceis varia de pessoa para pessoa e é influenciada por vários fatores inter-dependentes e inter-relacionados, tais como suas experiências anteriores, suas crenças e sua forma de estabelecer relações interpessoais. ${ }^{(27)}$

Quando um sujeito adoece, não é apenas o órgão doente que o faz sofrer. Existem muitos significados associados ao órgão acometido, neste caso o seio, bem como ao que a doença e o órgão possam significar e quais serão os impactos disto na história pessoal, sexual, de cada um. A mastectomia, comumente, por si só causa uma sensação de horror, além da questão de se observar a pele colada nas costelas sem o órgão que antes preenchera aquele espaço, o que é uma imagem que impõe à paciente o dado de realidade da cirurgia de mutilação. ${ }^{(28)}$

Através dos relatos obtidos nas entrevistadas, foram observadas diferentes formas de lidar com o novo arranjo físico pós-cirúrgico. No entanto, notou-se que a perda da mama foi invariavelmente vivenciada de maneira negativa pelas quatro pacientes, elas trouxeram preponderantemente sentimentos como medo do resultado estético da mastectomia, vergonha de se apresentar socialmente sem a mama e receio de olhar para o local da cirurgia, o que está em concordância com o estudo de Zecchin, ${ }^{(28)}$ descrito em seu livro A Perda do Seio, no qual ela coloca, entre muitas outras coisas, as implicações destes sentimentos na autoestima da paciente e pontua que estas emoções podem levar ao comportamento de isolamento social, em que as pacientes evitam se olhar e serem olhadas.

$\mathrm{Na}$ coleta de dados realizada através das entrevistas do período pré-cirúrgico, a Paciente ol traz o medo do resultado da mastectomia e a dificuldade que, em geral, ela acredita que irá sentir para se vestir, constituindo-se momentos geradores de ansiedade, pelo fato de não saber como ficará o lo- cal da mama após a realização da cirurgia, relacionando a perda do seio com uma vivência de não-perfeição do corpo:

Porque a gente tá se vendo aqui hoje, eu tô com meus seios, tudo bem, está com o nódulo, mas ainda está perfeito. Eu não sei amanhã, se tiver de tirar como é que eu vou me vestir, entendeu?

A Paciente 02 , no pré-cirúrgico, também se refere ao sentimento de que será difícil esta adaptação e a percepção do novo arranjo físico:

[...] é como se faltasse um pedaço de você. É complicado, muito complicado. Você quer se sentir bem, você quer se sentir bonita, é a questão de estética mesmo, né? Eu não sei se eu vou querer me olhar, eu não sei se eu vou, eu não sei. Eu não sei.

Todas as quatro entrevistadas demonstraram que após a descoberta do diagnóstico e durante o tratamento neo-adjuvante (terapêutica realizada antes do procedimento cirúrgico), houve uma possível reflexão sobre como seria a percepção pós-cirúrgica, demonstrando também aspectos de ressignificação subjetiva da experiência traumática do adoecimento. Como ilustração disto, percebe-se a fala da Paciente 03 que diz que:

[...] a gente tá acostumada a ver todos os órgãos, eu sei que daqui a mais ou menos um mês eu não vou ter mais essa probabilidade [...] é difícil, pra gente é muito dificil. [...] é um repensar da sua vida, a partir de agora, com todas as orientações que você tem que seguir [...].

E a Paciente 04 agrega dizendo que:

[...] Ele (Deus) não faz nada mal feito, tudo tem um propósito sempre bom na vida da gente [...] mas também tem ainda esse momento aqui, a cirurgia, esse momento não é agradável, a retirada não é agradável, ninguém me diga que é bom porque não é bom.

No que diz respeito à percepção real do pós-cirúrgico, percebemos que cada uma das pacien- 
tes teve uma vivência particular e subjetiva do seu processo, podendo ser melhor ou pior do que imaginavam que seria. A Paciente or teve uma vivência melhor do que a esperada, o que pode ser evidenciado através desta fala:

Na realidade, é uma coisa assim, que a gente sente a falta, mas pra mim não foi assim essas coisas não [...] Porque é constrangedor, é claro, a gente é mulher e tem vaidade, sente, mas eu não me abalei tanto como eu imaginava. [...] quando fiz logo a cirurgia, que não podia usar nada, foi aquela coisa, as roupas 'tudo' feias [...] depois da prótese (de sutiã) aqui não deu muita diferença.

Já a Paciente 03, discursa sobre uma experiência mais desagradável do que a esperada:

Foi pior do que eu imaginava que pudesse ser, né? Porque quando a gente fala que vai fazer, a gente pensa que é uma cirurgia, é simples, é uma cirurgia simples tudo, mas que a simples falta da mama na mulher, eu não sabia que fazia tanta diferença, né? Tanto que, pra mim, assim nos primeiros sete dias eu não consegui olhar e eu não conseguia chegar de junto de um local onde eu pudesse refletir diante de um espelho, porque todas as vezes que eu chegava era uma coisa inconsciente, mesmo, não sei, me dava vontade de chorar, eu só fazia chorar, chorar, entendeu?

As Pacientes 02 e 04 reforçam o impacto negativo causado pela percepção da falta da mama, compreendido como símbolo de feminilidade:

É assim, é uma sensação horrível, você fica com medo, você fica com medo de se olhar, né? [...] Não sei se era a falta do órgão em si ou se era o medo de ver a cirurgia em si, certo? [...] tem a questão da vaidade mesmo da mulher, né? Que isso afeta, você fica triste, nem toda roupa você pode vestir, você quer vestir uma roupa, quando você vê as pessoas normais, que você se olha que vê esse espaço (aponta para o local da cirurgia), mas tá dando pra levar, né? Paciente 02
A sensação é horrivel, né? [...] A perda do cabelo e a falta da mama, apesar de que já fiz colocando o expansor, já fiz com a reconstrução, não é bonito, não é agradável, né? Tem horas que a gente se olha assim, e se eu ficar muito tempo no espelho ainda acho assim esquisito, me acho esquisita, né? Me acho diferente e pra mim todo mundo tá percebendo, ainda mexe com uma parte emocional. Paciente 04

Deste modo, nota-se que a perda do seio é algo que toca direta e fortemente a vivência da feminilidade. Nota-se também que, para estas mulheres, olhar para o local da mastectomia e se dar conta de que a mama não está mais presente no corpo, é algo extremamente mobilizador do ponto de vista emocional e psicológico.

Cardozo e Guareschi(25) compreendem que a concepção de corpo na sociedade atual é a de algo que é adquirido e construído como uma conquista pessoal. Sendo assim, pensar no processo mutilatório da mastectomia é visualizar uma interdição desta conquista, ou seja, é quando a paciente se confronta com a perda de controle sobre a configuração do seu próprio corpo.

\subsection{A QUIMIOTERAPIA E SEUS IMPACTOS PSICOLÓGICOS}

Quimioterapia é o nome genérico para o tipo de procedimento no qual se utilizam substâncias químicas a fim de tratar, a nível celular, uma doença. No entanto, o conceito foi se restringindo ao uso de químicos no tratamento do câncer e hoje ele pode ser considerado como uma forma de tratamento que emprega medicamentos para destruir as células doentes que formam um neoplasma (tumor). ${ }^{(29)} \mathrm{O}$ uso da quimioterapia para tratar esta patologia teve início em 1946 e tem sido utilizado como recurso para reduzir, ou até mesmo inibir, o crescimento celular desordenado através do bloqueio das vias metabólicas. Sua utilização é feita em intervalos para que os tecidos normais se recuperem. ${ }^{(25)}$ 
Dentro do corpo humano, cada medicamento age de forma diferente. Por esta razão são utilizados vários tipos a cada vez que o paciente recebe o tratamento. Os medicamentos quimioterápicos misturam-se com a corrente sanguínea e são levados a todas as partes do corpo, o que possibilita a destruição das células comprometidas e impede que estas se espalhem pelo corpo.(1)

A administração do tratamento quimioterápico é realizada por enfermeiros especializados e auxiliares de enfermagem, e pode ser administrado por diferentes vias. $\mathrm{Na}$ quimioterapia por via oral o paciente recebe a medicação em forma de comprimido, cápsula ou líquido, podendo fazer uso em sua própria casa, sem auxílio profissional. $\mathrm{Na}$ administração intravenosa, o quimioterápico é aplicado diretamente na veia ou por meio de um cateter, sob injeção ou no soro. $\mathrm{Na}$ forma intramuscular, o medicamento é aplicado em injeção no músculo. E existe ainda a aplicação subcutânea (injeção aplicada por baixo da pele), a intracraneal (forma menos freqüente na qual se aplica a medicação no líquor da espinha dorsal), feita pelo próprio médico em consultório ou no centro cirúrgico e a tópica, quando o medicamento é aplicado na região afetada sob forma de líquido ou pomada. (1)

A quimioterapia tem como principais efeitos colaterais a mielossupressão (supressão do recurso que produz as células sanguíneas da medula óssea), imunossupressão (redução da eficiência do sistema imunológico), náuseas, vômitos, alopecia (queda de cabelos e outros pêlos do corpo), estomatite (infecção da cavidade bucal), fraqueza no corpo, diarréia, perda ou aumento de peso, feridas na boca e tontura. ${ }^{(25,1)}$

Todas as quatro pacientes entrevistadas fizeram uso de quimioterapia intravenosa sob uso de cateter. Elas trazem a sensação de intenso desconforto gerado pelos efeitos da quimioterapia, sobretudo a alopecia. Para elas o incômodo não estava no momento da administração do quimioterápico, mas sim nas reações que ele causa no organismo a longo prazo. Como exemplo, observa-se a seguinte fala da Paciente or no seu pós-cirúrgico: “[...] a que- da de meu cabelo me constrangeu mais do que 'meus peito'. Porque o cabelo tinha que usar lenço o tempo todo, tinha que todo dia usar peruca [...]."

Camargo, ${ }^{(12)}$ em sua tese de doutorado, descreve que para as vinte e cinco pacientes entrevistadas, todo o conteúdo sobre a quimioterapia envolve sofrimento, muito mal estar e impedimento de levar uma vida normal, o que foi confirmado também na presente pesquisa, uma vez que as pacientes entrevistadas trouxeram em seu discurso muitos incômodos ligados ao processo quimioterápico.

Para exemplificar, pode ser utilizada a fala da Paciente 03: “[...] as primeiras 'quimios' tem dia que você diz assim 'meu Deus, acho que isso é próximo à morte', porque a reação é muito chata, entendeu?". Esta fala demonstra o quão desconfortável é para as pacientes se submeter à quimioterapia. As pacientes também trouxeram a quimioterapia como um processo que gera mais sofrimento físico, emocional e social do que a cirurgia de retirada do seio.

Em contrapartida, Camargo ${ }^{(12)}$ observou que mesmo com o medo gerado pelo tratamento quimioterápico e por suas reações adversas e, ainda com o esforço para se adaptar a uma nova rotina e às mudanças pessoais que ocorrem com o início da quimioterapia, a mulher aceita que não há outra maneira de escapar do que mais teme após o adoecimento, que é a morte. Com este pensamento, adere ao tratamento, compreendendo que sem o mesmo a cura não será possível, o que faz com que a perda do cabelo, o mal-estar físico, a falta da mama ou de parte dela, não sejam mais aspectos prioritários, a prioridade agora passa a ser salvar a vida, recuperando a saúde.

$\mathrm{Na}$ presente pesquisa, observou-se que, embora as falas das pacientes reforcem esta autora no que diz respeito aos propósitos de adesão ao tratamento, as implicações geradas pelo mesmo não são secundárias, aparecendo como intensos incômodos geradores de altos níveis de ansiedade e sofrimento psíquico. Como é exemplificado na fala da Paciente 02:

Porque não é fácil não, você ter seu cabelo, você sair, né? Todo dia você arrumar, escovar e sair, $e$ 
depois você fazer uso de um lenço, você ter que usar um lenço por um tempo indeterminado, né? [...] Mas você não sabe até quando você vai usar, nem quanto tempo seu cabelo vai demorar [...] até ele crescer e você tirar o lenço.

Deste modo, nota-se que a submissão ao tratamento quimioterápico é, muitas vezes, desorganizador do ponto de vista psicológico, pois é uma fase em que a paciente se confronta o tempo inteiro com sua condição de portadora de câncer, uma vez que ela precisa lidar com a alteração da sua imagem corporal. Passar em frente ao espelho e perceber-se sem cabelo, precisar utilizar peruca e/ ou lenço é, também, confrontar sua identificação com o feminino, com o ideal de beleza socialmente definido, é lidar com a frustração de estar impossibilitada de ter algo simbolicamente feminino, que é o cabelo. As mudanças na rotina, como por exemplo, a necessidade de colocar lenço/peruca ao invés de pentear o cabelo, as adaptações na alimentação, podem ser traduzidas como sofrimentos paulatinos os quais a paciente vai precisar se acostumar a lidar a cada dia de enfrentamento do seu processo de adoecimento, vislumbrando a cura.

O acompanhamento psicológico nesta fase, bem como em todas as etapas do adoecimento/ tratamento, é de grande valia, a fim de possibilitar à paciente uma reflexão acerca da sua nova realidade e das mudanças, muitas vezes irreversíveis, que irá sofrer a partir desse momento. $O$ trabalho psicológico também pode agir no sentido psicoeducativo, avaliando o nível de compreensão da paciente sobre $o$ adoecimento ao qual foi acometida e tratamento ao qual será submetida, a fim de facilitar seu enfrentamento psíquico e clarear possíveis dúvidas, o que facilitará sua comunicação com o médico assistente.

\subsection{O ESTIGMA DA MORTE}

Câncer e morte são dois termos altamente associados. Pensar nesta patologia certamente envolve pensar nesta possibilidade. $O$ câncer acentua a ameaça de morte, inclusive porque no imaginário social, esta é uma das enfermidades mais associadas à questão do óbito na contemporaneidade. ${ }^{(30)}$

Ao longo da História, o câncer é compreendido como uma patologia que inexoravelmente leva à morte, apesar de já podermos contar, nas últimas décadas, com muitos progressos da medicina em relação ao seu tratamento, tais como procedimentos cirúrgicos e farmacológicos, bem como o surgimento da radioterapia, ainda hoje ele carrega o estigma de doença fatal. ${ }^{(30)}$

O significado do fenômeno da morte não se encerra em sua dimensão natural ou biológica. A morte inclui, como qualquer outro evento da vida humana, uma dimensão social. ${ }^{\left({ }^{\circ}\right)}$ Como seres humanos, nos diferenciamos dos outros animais justamente pela consciência de finitude da nossa existência: é fato que inexoravelmente morreremos. ${ }^{(30)}$

Para o paciente, o câncer traz em si a consciência da possibilidade real de morte, e esse pensamento geralmente vem permeado de angústia e temores que o acompanham durante todo o tratamento. Nesse sentido, o medo é a resposta psicológica mais comum diante da possibilidade de morte, sendo este universal, abrange todas as pessoas, independente de sexo, idade, nível sócio-econômico e crença religiosa, e se apresenta com diversas facetas e é composto por inúmeras dimensões. ${ }^{\left({ }^{11}\right)}$

Ao longo do processo de desenvolvimento humano, percebe-se a interface entre a vida e a morte, por esta razão é inevitável refletir sobre como o sujeito acometido por uma doença grave, tal como o câncer, lida com questões que envolvem a morte e o processo do morrer. A tomada de consciência real da finitude da própria vida é um processo sem dúvida ansiogênico, mas a ansiedade diante da morte é, na verdade, um reviver de ansiedades anteriores, relacionadas a perdas e quebras de vínculos, e não deve ser subestimada, uma vez que leva o paciente a encarar as ameaças da imprevisibilidade, o que propicia o desenvolvimento de recursos de enfrentamento. A morte em si nem sempre é um problema para o paciente, mas sim, o medo de morrer, que nasce do sentimento de desesperança, de desamparo e isolamento que o segue. ${ }^{(30)}$ 
O medo da morte não é um medo único, ele pode incluir o medo de muitas outras coisas, como por exemplo, da solidão, da separação de quem se ama, do desconhecido, da interrupção de planos e sonhos, do que pode acontecer aos que ficam, e, numa visão espiritual, do julgamento de suas ações durante a vida. Cada sujeito certamente teme mais de um aspecto da morte, e isso vai depender de questões internas do indivíduo que a enfrenta, seja ele quem está morrendo ou quem está perdendo uma pessoa querida. ${ }^{(30)}$

Ao longo das entrevistas, percebeu-se a dificuldade das pacientes para falar da temática da morte, mas, ainda assim, este foi um tema recorrente nas primeiras entrevistas, não voltando a ocorrer nas entrevistas do pós-operatório. Concordando com Kovács, ${ }^{(30)}$ no que diz respeito à multiplicidade de medos envolvidos no medo de morrer, a $\mathrm{Pa}$ ciente $\mathrm{O} 2$ resume seu pensamento no momento do diagnóstico da seguinte maneira:

E você, quando você, acontece um negócio desse, você fica com medo de morrer, claro, né? A primeira coisa que vem é aquele pavor: 'vou morrer'. Aí você associa a doença com a morte; a doença, o problema como não tem cura, né? Você fica com medo, o tempo vai passando e você vai vendo que não é assim, né? Você pode não estar curado, mas você também não está condenado à morte pra vida inteira. E a preocupação, a preocupação maior eu acho que todo mundo, de mãe principalmente, é de deixar seus filhos, principalmente quando ainda são crianças, ainda são dependentes de você.

Borges $^{(30)}$ e Kovács ${ }^{(31)}$ concordam ao afirmar que socialmente o câncer é altamente ligado à vivência da real possibilidade de morte e neste estudo foi possível notar que, muitas vezes, o primeiro pensamento quando se recebe este diagnóstico é associar tal patologia à morte. A Paciente 03 , por exemplo, coloca que:

E aí na hora é um choque, você só pensa assim: 'poxa, tenho quanto tempo de vida?', é a única coisa que vem na sua cabeça [...] você acha assim, que o mundo acabou, é a primeira impressão que você tem é que o mundo acabou, provavelmente ali, naquele momento, não tem mais jeito pra nada e pra você desconstruir isso dentro de você e construir que existe uma perspectiva, que o câncer tá aí, mas que existe uma forma hoje, um tratamento que lhe dá uma condição melhor demorou um pouco.

Percebe-se que mesmo quando o conteúdo da morte não aparece claramente, ele permeia o discurso da paciente, como é o caso da Paciente 04: "Ainda eu não quis fazer, pensar muito sobre esse futuro porque eu só sei que eu vou viver [...]". Esta forma indireta de falar sobre o assunto pode ser compreendida como uma maneira de minimizar o desgaste e o sofrimento psíquico gerados pela percepção da própria finitude.

Conclui-se, contudo, que segundo a presente pesquisa, o confrontamento com a possibilidade real de morte é algo que está mais associado ao primeiro contato com o diagnóstico recebido pela paciente, sendo uma postura reativa diante do medo de enfrentar uma doença tão estigmatizada socialmente, o que está em concordância com Borges et al. ${ }^{(30)}$ quando ele afirma que o sujeito, ao se saber portador de câncer, coloca em xeque sua própria existência e atribui um sentido para sua doença e seu tratamento. Em muitas situações, o câncer traz, inevitavelmente, a idéia do fim da vida e de todas as suas possibilidades, deste modo, o medo se faz presente, e como tal merece reflexão, pois traz sofrimento. Pensar na morte nos faz pensar na própria vida e em como a estamos vivendo.

Através das entrevistas realizadas foi possível notar que o medo da morte não vem sozinho, ele é acompanhado do medo da solidão, do medo de ficar impossibilitada de realizar as atividades antes realizadas, do medo do desconhecido da morte, do medo de abandonar as pessoas que se ama.

O psicólogo, nesse caso, pode intervir no sentido de possibilitar ao paciente uma reflexão sobre esses medos, visando uma possível ressignificação da experiência do contato com sua própria finitude. 
O paciente precisa ser escutado e se sentir acoIhido na genuinidade do seu sofrimento, para que seja auxiliado no enfrentamento do medo da própria morte iniciado pela sua doença e/ou pelo seu processo de terminalidade. $O$ trabalho de intervenção psicológica abre um espaço para os pacientes falarem daquilo que for de seu desejo, considerando que a ênfase deve ser na qualidade de vida e em sua ressignificação.

Pensar na morte, sobretudo na própria morte, é entrar em conflito com aspectos conscientes e inconscientes, o que pode ser perturbador do ponto de vista narcísico, uma vez que, segundo Kovács, ${ }^{(31)}$ existe uma sobre determinação em nossas vidas, advinda de instâncias inconscientes, o que provocou uma ferida narcísica na humanidade que se percebeu não sendo mais dona de seus atos e comportamentos. Por dada razão, pensar na morte - aliás, no desconhecido como um todo - é tão perturbador, porque nos coloca em contato com nossa limitação, o fato de não podermos apreender o mundo na nossa consciência, no nosso conhecimento, ou seja, não podemos ser detentores de todas as informações que circundam a vida, nem tampouco as que abrangem a morte.

\section{CONSIDERAÇÕES FINAIS}

O saber-se portador de câncer é, em geral, aterrorizante, porque apesar dos avanços terapêuticos que permitem uma melhoria na taxa de sobrevida e na qualidade de vida do paciente, permanece o estigma de doença dolorosa, incapacitante, mutilante e mortal. ${ }^{(12)}$

Esta pesquisa mostrou que o recebimento do diagnóstico de câncer faz com que o sujeito adoecido, inexoravelmente, reflita sobre a possibilidade de estar recebendo uma sentença de morte e se questione sobre a finitude da sua vida, pensando sobre seus limites e suas possibilidades. Mesmo com tantas inovações da medicina, vê-se que desconstruir o estigma de doença que leva sempre à morte é algo difícil de ser alcançado, mesmo que o paciente já se encontre em assistência clínica ou ainda tenha uma doença inicial.

A mastectomia, o mais invasivo procedimento cirúrgico para tratar o câncer de mama, traz graves implicações para a vida e para a imagem corporal da paciente. Embora este não seja um recurso terapêutico utilizado em todos os casos, ele é bastante freqüente e gera repercussões emocionais relevantes, alterando não apenas a imagem física, como também a imagem psíquica que a paciente tem de si mesma. ${ }^{(4)}$

Deste modo, este estudo tem relevância devido ao fato de que o psicólogo se depara com uma variedade muito grande de patologias, diagnósticos e prognósticos dos seus pacientes, sendo a mutilação física uma possibilidade de conseqüência de alguns desses processos. Sendo assim, é pertinente que este profissional possa compreender melhor os sentimentos marcantes e significativos desta fase, bem como as diferentes reações psicológicas que podem acompanhar esta alteração física.

No que diz respeito à assistência ao paciente oncológico, indica-se que esta seja feita por uma equipe multidisciplinar, a fim de promover ao paciente o tratamento mais integral possível. Pensar o paciente de maneira holística poderá facilitar a comunicação entre este e a equipe, sendo o psicólogo um profissional que pode atuar na interlocução desta dinâmica.

O acompanhamento psicológico nas fases do tratamento oncológico é de grande valia para o paciente, a fim de permitir a este uma possibilidade de reflexão acerca da sua nova realidade e das mudanças, muitas vezes irreversíveis, que irá sofrer a partir deste momento. $O$ trabalho do psicólogo também pode ser no sentido psicoeducativo, ao passo que ele avalia o nível de compreensão do sujeito sobre seu adoecimento e sobre o tratamento ao qual será submetido, a fim de facilitar seu enfrentamento psíquico e clarear possíveis dúvidas.

A retirada total da mama, bem como qualquer tipo de amputação, é um procedimento invasivo e doloroso física e psicologicamente, pois tira da pessoa parte do seu corpo. Por isto, faz-se neces- 
sário elaborar o luto daquela perda e ressignificar o sentido daquele órgão e, muitas vezes da própria vida, a fim de viabilizar perspectiva e condições de reabilitação.

Diante de todo o exposto pelas pacientes nas entrevistas, foram selecionadas quatro categorias de análise do discurso, quais sejam: a fé como estratégia de enfrentamento; o feminino e sua estética; a quimioterapia e seus impactos psicológicos; e o estigma da morte.

Com todo o desgaste físico e emocional gerado pelo adoecimento e suas consequências, é necessário que se criem estratégias de adaptação à nova realidade que se põe. Deste modo, observou-se que as pacientes entrevistadas desenvolveram estratégias de enfrentamento do adoecimento, sendo utilizado de modo mais freqüente e intenso o pensamento positivo possibilitado pela fé em Deus. Conclui-se com isso que a crença numa força superior é algo que possibilita e potencializa o estabelecimento da confiança no tratamento e no pensamento de que há possibilidade de se obter a cura.

Sendo assim, é possível se dar conta de que a equipe multidisciplinar de assistência, sobretudo em se tratando de pacientes oncológicos, em seus muitos atributos, pode otimizar o tratamento do paciente e o compreender melhor subjetivamente se tiver ciência de algumas de suas crenças. Uma equipe que se importa com a história de vida, com os medos e com as verdades do paciente inexoravelmente vai poder atendê-lo de maneira mais objetiva e personalizada, e isto certamente terá um efeito subjetivo importante no psiquismo do paciente.

Comumente se associa a preocupação com a estética como um comportamento intrinsecamente feminino. Embora a sociedade encontre-se em período de transição de valores relacionados ao feminino e ao masculino, isto ainda é algo vigente. Nesta pesquisa foram trazidos conteúdos sobre a beleza feminina e as alterações físicas pelas quais a paciente pode passar ao longo do tratamento de câncer de mama. Notou-se, no entanto, que a estética, no sentido em que foi retratada, não diz respeito apenas ao que é belo ou não, mas se re- fere a um estar no mundo, a uma identidade e a uma identificação entre pares, que quando deixa de acontecer, torna-se um evento gerador de sofrimento psíquico.

A integração do psicólogo à equipe de assistência a pacientes oncológicos é de extrema valia. $\mathrm{O}$ trabalho deste profissional vem no sentido de acoIher o sofrimento gerado por este processo e potencializar a reflexão daquele momento da história de vida do paciente, resgatando o seu lugar no mundo enquanto sujeito, para que ele possa continuar identificando a si mesmo para além do câncer.

Como na maioria das pesquisas, ao fim deste trabalho foram observados limites e possibilidades decorrentes do mesmo. Enquanto trabalho de conclusão de curso de uma graduação, este estudo não conseguiu abranger todos os aspectos e as temáticas encontrados nas falas das pacientes, uma vez que isto exigiria um trabalho mais extenso e mais embasado teoricamente. Neste sentido, este mesmo ponto limitador abre uma interessante possibilidade de desdobrar este estudo em outros, como, por exemplo, um mestrado dentro na área de Psico-oncologia.

Devido à alta incidência e à constante mobilização emocional dos pacientes e seus familiares frente ao câncer, nota-se que esta temática não se esgota, mas sim se atualiza e necessita de pesquisas que toquem a subjetividade envolvida neste processo.

\section{REFERÊNCIAS}

1. INCA. Perguntas e Respostas sobre Quimioterapia. 2010. Disponível em http://www. inca.gov.br/cancer/PDF/perguntas_qt.pdf

2. Ministério da Saúde (BR). Controle do câncer de mama: documento de consenso. Brasília, DF: Ministério da Saúde; 2004.

3. Barros ACSD, Barbosa EM, Gebrim LH. Diagnóstico e tratamento do câncer de mama. São Paulo: Associação Médica Brasileira; Brasília: Conselho Federal de Medicina; 2001. Projeto Diretrizes. 
4. Rossi L, Santos MA de. Repercussões psicológicas do adoecimento e tratamento em mulheres acometidas pelo câncer de mama. Psicol. cienc. prof. 2003;23(4):32-41.

5. Leloup J-Y. O corpo e seus símbolos: uma antropologia essencial. Petropólis, RJ: Vozes; 1998.

6. Adami F et al. Aspectos da construção e desenvolvimento da imagem corporal e implicações na educação física. EFDeportes. com, Revista Digital - Buenos Aires, 2005;10(83).

7. Bittencourt BRS. Amputação e estratégias defensivas. Palhoça, 2006.

8. Fraser MTD, Gondim SMG. Da fala do outro ao texto negociado: discussões sobre a entrevista na pesquisa qualitativa. Paidéia. 2004;14(28):139-152.

9. Minayo MC de S. Modalidades de abordagens compreensivas. O desafio do conhecimento: pesquisa qualitativa em saúde. São Paulo: Hucitec; 2007.

10. Lôbo RC de MM, Santos N de O, Dourado G, Lucia MCS de. Crenças relacionadas ao processo de adoecimento e cura em mulheres mastectomizadas: um estudo psicanalítico. Psicol. hosp. 2006;4(1).

11. Lester SC. A mama. In: Kumar V, Perkins JÁ. Robins \& Cotran. Patologia: bases patológicas das doenças. Rio de Janeiro: Elsevier; 2005.

12. Camargo TC. O ex-sistir feminino enfrentando a quimioterapia para o câncer de mama: um estudo de enfermagem na ótica de Martin Heidegger. Rio de Janeiro: UFRJ; 2000.

13. Soares CP. Há uma psicanálise do corpo? In: Moura MD de, organizador. Psicanálise e hospital: a criança e sua dor. Rio de Janeiro: Revinter; 1999.

14. Reich, s/d. Apud Leloup J-Y. O corpo e seus símbolos: uma antropologia essencial. Petropólis, RJ: Vozes; 1998.

15. Nasio J-D. Meu corpo e suas imagens. Rio de Janeiro: Jorge Zahar Ed.; 2009.

16. Albuquerque L, Falkenbach AP. Imagem corporal em indivíduos amputados. EFDeportes. com, Revista Digital - Buenos Aires. 2009;14(131).

17. Ferreira $A B$ de $H$. Novo dicionário da língua portuguesa. Rio de Janeiro: 2005.

18. Chini GC de O, Boemer MR. A amputação na percepção de quem a vivencia: um estudo sob a ótica fenomenológica. Rev. latinoam. enferm. 2007.

19. Nasio J-D. O livro da dor e do amor. Rio de Janeiro: Jorge Zahar Ed.; 1997.

2O. Rey FLG. Sujeito e subjetividade: uma aproximação histórico-cultural. São Paulo: Pioneira Thomson Learning; 2003.

21. Faria JB, Seidl EMF. Religiosidade e enfrentamento em contextos de saúde e doença: revisão de literatura. Psicol reflex. crit. 2005;18(3):381-389.

22. Costa P, Leite RCBO. Estratégias de enfrentamento utilizadas pelos pacientes oncológicos submetidos a cirurgias mutiladoras. Rev. bras. cancerol. 2009;55(4):355-364. São Paulo.

23. Folkman, Lazarus, Gruen \& De Longis, 1986. Apud Faria JB, Seidl EMF. Religiosidade e enfrentamento em contextos de saúde e doença: revisão de literatura. Psicol reflex. crit. 2005;18(3):381-389.

24. Pargament et al., 1988. Apud Faria JB, Seidl EMF. Religiosidade e enfrentamento em contextos de saúde e doença: revisão de literatura. Psicol reflex. crit. 2005;18(3):381-389.

25. Cardozo M da C, Guareschi NMF. O corpo do espelho, o corpo para o espelho: um estudo sobre o câncer de mama. In: Strey MN, Cabeda STL, organizadores. Corpos e subjetividades em exercício interdisciplinar. Porto Alegre: EDIPUCRS; 2004.

26. Capisano, 1986. Apud Cardozo M da C, Guareschi NMF. O corpo do espelho, o corpo para o espelho: um estudo sobre o câncer de mama. In: Strey MN, Cabeda STL, organizadores. Corpos e subjetividades em exercício interdisciplinar. Porto Alegre: EDIPUCRS; 2004.

27. Sontag, 1984. Apud Cardozo M da C, Guareschi NMF. O corpo do espelho, o corpo para o espelho: um estudo sobre o câncer de mama. In: 
Strey MN, Cabeda STL, organizadores. Corpos e subjetividades em exercício interdisciplinar. Porto Alegre: EDIPUCRS; 2004.

28. Zecchin RN. A perda do seio: um trabalho psicanalítico institucional com mulheres com câncer de mama. São Paulo: Casa do Psicólogo: FAPESP: EDUC; 2004.

29. Yamaguchi NH. O câncer na visão da oncologia. In: Carvalho MMMJ. De, coordenador.
Introdução à Psiconcologia. Campinas, SP: Psy; 1994.

30. Borges ADVS, Silva EF da, Toniollo PB, Mazer SM, Valle ERM do, Santos MA dos. Percepção da morte pelo paciente oncológico ao longo do desenvolvimento. Psicol. estud. 2006;11(2):361369.

31. Kóvacs MJ. Morte e desenvolvimento humano. São Paulo: Casa do Psicólogo; 1992. 